\title{
The impact of out-of-school factors on motivation to learn English: Self-discrepancies, beliefs, and experiences of self-authenticity
}

(This is the pre-publication of Henry A. \& Cliffordson, C. (2015). The impact of out-of-school factors on motivation to learn English: Self-discrepancies, beliefs, and experiences of selfauthenticity. Applied Linguitics. doi: 10.1093/applin/amv060 PDF:

http://applij.oxfordjournals.org/cgi/reprint/amv060? ijkey=H0O8hueFTWUiOrR\&keytype=ref)

\section{Introduction}

Globalisation is changing the nature of English language learning. Paradoxically, it has involved the strengthening of local interpretations, traditions and practices, all of which can vary enormously as a consequence of the particularities of local settings. Consequently localised contexts of learning are emerging that, as a result of unique combinations of cultural, social and linguistic factors, are highly distinct. Within this climate of "linguisticcultural heterogeneity” (Canagarajah 2007: 925) the relationships between individuals and the English-speaking identities they develop differ widely. Not only do differences exist between as well as within learning contexts, but because learners' goals and identities are embedded in local realities and contextual particularities, it is becoming ever more difficult to characterise interrelations between context, motivation and pedagogies in any general sense (Ushioda, 2013: 235).

The diversity of environments in which English is encountered and the varying affordances that individual learners attune to in these contexts present serious challenges for practitioners. As recognised by teachers in a number of European countries, while many students will readily engage with English in social practices outside school, they can often be reluctant to invest effort in formal learning (Henry 2013; Taylor 2013; Ushioda 2013). It is against this backdrop that, in a Swedish setting where English is near-ubiquitous in everyday environments and, for young people in particular, is the preferred medium of communication in many discourse practices, the current study seeks to understand the impact that out-of- 
school encounters with English can have on classroom motivation. Based on questionnairegenerated data from 116 upper secondary students, and drawing on emerging research into, (i) differing types of English language-speaking identities and their impact on the selfdiscrepancies at the heart of the motivational process, (ii) students' beliefs about the relative efficacy of language learning in instructed and natural environments, and (iii) differing experiences of self-authenticity when engaging with English in varying social contexts, the study seeks to consider the effects these phenomena can have on motivated behaviour in instructed learning.

\section{Discrepancies between current and ideal L2 selves}

\section{Notions of identity in $\mathbf{L} 2$ motivation research}

The previous decade's paradigm shift in L2 motivation research came about in no small part as a consequence of the recognition that learners of English develop an identification with the "sociocultural loading” of global English, and that this identification is "associated with a non-parochial, cosmopolitan, globalized world-citizen identity” (Dörnyei \& Ryan, 2015: 79). However, irrespective of whether motivation to learn English is conceptualised as stemming from a perception of wanting to become part of a wider, global community, or from an identification with a particular ethnolinguistic group (Gardner and Lambert 1972), L2 motivation researchers have generally regarded the individual's language-speaking/learning identity to be bilocular. That is to say that, in addition to a locally-grounded and L1-mediated identity, a separate dimension of the learner's identity derives from an affinity with, and aspiration to become part of a wider, imagined community of target language (TL) speakers. ${ }^{\mathrm{i}}$

In their seminal investigations of L2 learners' identifications with other ethnolinguistic groups, Gardner and his colleagues argued that, when affiliations with another community are established, the individual is likely to develop a 'bicultural identity' which encompasses the 
sense of a membership of both their own, and the other group (Lambert 1972: 232). Even though the shift of focus from out-group identifications to internal domains of the self has changed the ways in which the generation of effortful behaviour is understood, conceptualisations of identity in L2 motivation research continue to stress its bilocular nature (see e.g. Stracke, Jones and Bamley 2014). Drawing on Arnett’s (2002) work on the impact of globalization on identities, and his contention that some aspects of a person's identity remain locally-rooted (deriving from participation in local cultural practices) while others are global in nature (stemming from an awareness of and participation in a broader global culture), Lamb (2004) similarly suggests that learners of English develop ‘bicultural identities’. Enabling affiliations with both local and global communities, Lamb explains how, for the Indonesian students he studied, a bicultural identity meant that they could simultaneously be ‘both a Sumatran Indonesian and an Indonesian world citizen’ (2004: 15).

Although the L2 identities of students learning English as an international language have not been widely investigated in motivation research, support for a bilocular conceptualisation of the type proposed by Lamb (2004) has been found in different contexts. In a German setting Erling (2007), for example, reported that the sociolinguistic profiles of the students she surveyed indicated that they 'no longer conceive of themselves as just citizens of a nation', but also recognise 'the potential of English for participating in various global communities that use the language’ (126). Similarly, in a study carried out in Hong Kong, Sung (2014) found that learners of English had distinct local and global identities, and that while some 'preferred to foreground either their local or global identities’ (47), others favoured displaying 'both their local and global identities simultaneously’ (49).

\section{Self discrepancies and the generation of motivation}


Framed in the context of self-discrepancy theory (Higgins, 1987), motivated behaviour to learn English is conceptualized as the outcome of ongoing processes in which learners work on developing the global element of a bicultural identity. That is to say, motivation is generated by a desire to reduce the gap between the individual's current self-image as a 'global citizen' and the image of themselves as a global citizen in the future (Dörnyei, 2005). However while in many settings the future image of being a global citizen (reflecting the global part of the person's bicultural identity) will function as a powerful target to aim at, it may not do so in all. In contexts where the influence of global flows of digital medias is profound, where, through processes of adaptation, appropriation and restyling (Allen 2011), domestically produced medias subtly take on the forms of foreign counterparts, and where in everyday interaction people participate in globally-oriented, English-mediated discourse practices, identities that comprise distinctly 'local' and 'global' dimensions may be hard to discern (Henry and Goddard 2015). In such contexts, as Arnett (2002) suggests, rather than developing bicultural identities, people may instead develop hybrid identities.

Hybrid identities, as Arnett makes clear, emerge when local cultures become modified by globalisation. As 'local’ cultures become increasingly indistinct, so too, he contends, do 'local' identities. In a hybrid identity local and global cultures merge (Hermans and DiMaggio 2007). Rather than living in or affiliating with particular cultures (as implied in bilocular conceptualisations of identity), people instead find themselves on the interfaces between cultures. They find themselves in contexts where cultures interact and interconnect. This, Hermans and DiMaggio (2007) argue, impacts on identity as it is in the self of the individual that different cultures 'come together and meet' (35). Consequently, in many contemporary societies, hybridity (as opposed to the notion of a bicultural identity) can better capture the complexity of influences at play. 
In settings where exposure to English and participation in English-mediated discourse practices are extensive, people are likely to develop either a strong global identity or a hybrid identity that lacks distinguishably 'global' and 'local' components. These identity types have an impact on the nature of the visions people have of themselves as speakers/users of English. Specifically, for people in contexts where English is a part of everyday life, the discrepancy they perceive between their current L2 self and their ideal L2 self may not be as great as in contexts where English is not as prominent. Consequently, the contribution played by the Ideal L2 Self in generating motivation may not be as central as it is in settings where the impact of global cultures is less profound, and where the presence of English is less pervasive.

\section{Beliefs}

Recognising the need for more situated analyses of learners' motivation, researchers have begun to investigate 'key motivational cognitions' that can explain differences in students' approaches to classroom learning (Ushioda 2012: 61). These include learners' attributions and beliefs. The amount of effort an individual is prepared to channel into language learning is, to a degree, determined by beliefs held about the nature of learning and evaluations of previous successes and failures. Beliefs are subjective realities and, because beliefs about SLA are variable, context-embedded and complexly interrelated, they encompass not just matters that the individual perceives to be true (and is sufficiently confident about to act upon), but also knowledge which is contingently accepted as true (Barcelos 2003).

In SLA work on beliefs is informed by a number of mainstream theories. While for example Hsieh and colleagues (e.g. Hsieh and Schallert 2008) have explored language learners’ attributions, Mills and colleagues (Mills, Pajares and Herron 2007) have examined their self-efficacy beliefs. With regard to students’ beliefs about the relative efficacy of acquisition in naturalistic and instructed settings, work carried out by Mercer and Ryan (Mercer and Ryan 2010; Ryan and Mercer 2011, 2012) is of particular interest. Drawing on 
Dweck's (1999) research into the ways in which views about intelligence impact on the generation of motivation and willingness to engage in learning activities, Mercer and Ryan argue that strong beliefs about natural talent and the efficacy of acquisition in naturalistic settings can demotivate and disempower learners in the language classroom.

In their adaptation of Dweck’s incremental/entity theorist distinction, Mercer and Ryan identify two varieties of what they term 'language learning mindsets'. These mindsets, they hypothesise, regulate the approach students take to learning activities. A fixed language learning mindset, they argue, is characteristic of a person who holds the belief that successful language learning is attributable to natural talent or an innate ability. Someone who, on the other hand, holds the belief that language skills can be developed as a result of effort and practice is said to have a growth language learning mindset. For students with fixed language learning mindsets, Ryan and Mercer further argue that beliefs about the role of natural talent are related to beliefs about the value of time spent 'in a county where the language is widely spoken and the relative 'naturalness' of the language learning process' that takes place there. Making the point that, in a study abroad context, countries where English is spoken remain 'a constant background presence in foreign language learning', they contend that the need for effort can be negated and that classroom motivation can suffer (Ryan and Mercer 2011: 166).

Extrapolating from these ideas, it is not difficult to see how, in contexts where English is near-ubiquitous in social discourse practices, out-of-school encounters with the language form a similarly constant 'background presence' in instructed learning. Thus fertile ground for the development of fixed language learning mindsets that privilege naturalistic acquisition is provided. A mindset of this type can have a correspondingly negative effect on motivation to engage in formal learning since, within the meaning framework it creates, causal attributions will occur (Hong, Chiu, Dweck, Lin and Wan 1999). This means that in places where English is a part of the everyday social fabric, students who attribute proficiency gains to encounters 
with English in everyday activities (as opposed to practice and effort expended in school and on homework) are unlikely to regard effort expended on instructed learning as a particularly worthwhile use of cognitive resources (Henry 2014). Energies, consequently, may be channelled elsewhere.

\section{Experiences of self-authenticity}

In contexts where students have extensive encounters with English in everyday social practices (see reports from e.g. Belgium (Kupens, 2010), Finland (Piirainen-Marsh and Tainio, 2009) and Sweden (Sundqvist, 2009)), experiences in instructed settings and naturalistic contexts can be very different. While interactions in English-mediated digital environments (e.g. surfing the Net, playing digital games, engaging in online literacy practices such as commenting on/contributing to web forums or writing fan fiction, watching and creating films, video clips and vlogs etc.) can be engaging, creative and personally meaningful, experiences in school can be altogether different. Even in countries with progressive educational systems and curricula that promote intercultural aspects of language learning, English lessons tend to be textbook-centred and offer little scope for personal expression or the activation of what Ushioda (2011) refers to as students' 'transportable identities’ (for recent discussions see also Henry 2013; Taylor 2013). In settings where dissonances in students’ perceptions of in- and out-of-school encounters with English arise, Henry (2013) suggests that awareness of these differences can impact negatively on classroom motivation. Specifically, he maintains that the personally meaningful and highly valued cognitive, emotional and aesthetic experiences gained in digital environments can have the effect that students are encouraged to seek similarly self-congruent and aesthetically powerful experiences elsewhere. Transitioning into the regimented and often mundane environments of the language classroom, they are asked to engage in a very different type of social practice. Not only do language classrooms often offer little scope for autonomy in the 
learning process (Murray, Gao and Lamb 2011) and provide limited opportunities for personal expression (Ushioda 2011), but in school generally creativity and innovation go largely unrewarded (Hayes and Gee 2010). For students learning English in contexts where substantial periods of time are spent in English-mediated environments outside the classroom - and within which they engage in personally-meaningful activities - school settings offer few opportunities to experience similar types of aesthetic pleasure. The dissonances between these very different experiences can, Henry (2013) argues, lead to the emergence of an 'authenticity gap’.

Authenticity is the experience of being true to one’s self and is generated when a person does something that 'fits' with who they feel they are, and coheres with their own particular view of the world (Kernis \& Goldman, 2006; and in a SLA context see e.g. Kramsch, 2012). Experiences of authenticity are linked to other emotions, such as pleasure, satisfaction, contentedness and self-esteem. Authenticity can thus be regarded as an affective quality that people are motivated to obtain (Huta \& Waterman, 2013). Just as with other affective dimensions of motivation, a person will be encouraged to do something if they believe that the activity is 'authentic' and involves things that cohere or are congruent with their sense of self (Henry, 2013; Vannini \& Burgess, 2009). In contexts where students frequently engage in personally meaningful activities in their leisure time, a lack of congruence between their sense of self as a user/speaker of English in the classroom, and sense of self as a user/speaker of English in out-of-school domains can arise. Aware of a sense of disempowerment in classroom settings - the perception of lacking opportunities for self-realisation and an inability to act in ways that are self-relevant and 'authentic' - students can experience what Vannini and Burgess (2009) describe as a feeling of 'frustrated authenticity'. It is the negative emotion generated by experiences of dissatisfaction and lack of fulfilment associated with 
‘frustrated authenticity’ that, Henry (2013) contends, impacts negatively on motivated learning behaviour.

\section{Purpose}

In an increasing number of settings students are encountering English in parallel environments, in and out-of school. Not only is there often a substantial imbalance in the time spent in these environments, but activities pursued in out-of-school settings can be perceived as having greater personal meaning and as more identity-relevant. Drawing on emerging research within the L2 motivation field into, (i) differing types of English language-speaking identities and their impact on discrepancies between learners’ current and ideal L2 selves, (ii) students' beliefs about the efficacy of language learning in instructed and natural environments, and (iii) differing experiences of self-authenticity when engaging with English in different contexts, the purpose of this study is to consider the effects that these phenomena have on motivated behaviour in instructed learning. In the context of a setting where students have extensive out-of-school encounters with English, and using a design employing structural equation modelling (SEM) techniques, three hypotheses were constructed:

H1 (a) Scores on a scale measuring students’ ideal L2 selves would be comparable to or greater than those of similarly-aged students in 5 reference studies conducted in settings where out-of-school encounters with English are less extensive and proficiency levels not as high.

H1 (b) The correlation between the Ideal L2 Self and the criterion measure of intended effort in school would be substantially weaker than in the reference studies.

H1 (c) The lower proportion of variance on the criterion measure can be explained by the small discrepancy between the Current L2 Self and the Ideal L2 Self. 
H2 (a) Students' attributions relating proficiency in English to instructed learning would be positively related to the criterion measure of intended effort in school.

H2 (b) Students' attributions relating proficiency in English to natural ability and naturalistic out-of-school encounters would be negatively related to the same criterion measure.

H3 Students' experiences of supressed self-authenticity when speaking English in school would be negatively related to the criterion measure of intended effort in school.

\section{Method}

\section{Setting}

In recent years Sweden has experienced 'an overwhelming Anglicization' (Cabau, 2009: 134). A near-ubiquitous presence, English can be regarded as functioning 'as a second language in the Swedish daily living environment' (ibid.). In global terms, Swedish is a relatively small language (with a little over 10 million speakers worldwide), and in Sweden subtitled TV programs and films imported from the UK and USA constitute a large proportion of domestic offerings. People in Sweden have high levels of proficiency in English. For example, more 14-15 year-old students than in any other European country achieve CEFR B2 'upper intermediate user’ for receptive skills (European Commission 2012). A large majority of secondary and upper secondary students gain passing grades or higher in English. Students have positive beliefs about their capacity to use English, some $60 \%$ of primary school students in a recent study rating their skills in English as 'good' or 'very good' (Sundqvist and Sylvén 2014). In upper secondary schools CLIL programs are common (Sylvén 2013) and increasing numbers of university programs are provided in English (Airey 2009).

Access to high-speed broadband Internet is widespread and in a recent survey of 'networked readiness', Sweden topped the list of 142 countries (World Economic Forum 
2012). Ownership of computers and mobile devices is almost universal and use of the Internet and digital gaming are by far the most commonly reported free-time activities among 13-16 year-olds. Nearly half of all boys report playing digital games for more than three hours per day, the four most popular games being either English-mediated or frequently played using English-language settings (Swedish Media Council 2013). The three most popular TV series in the 13-16 age bracket are all broadcast in English. When other English-mediated activities - listening to music and reading books and magazines - are included in the overall picture, the amount of time young people spend in English-language environments is substantial (Sundqvist and Sylvén 2014). Sundqvist (2009), for example, found that outside school students spent on average over 18 hours per week in English-mediated environments, while Olsson (2011) found the average time to be in excess of 20 hours per week.

English is a core subject in the Swedish curriculum and most students start learning in the first grade (age 7). By grade 6 (age 12), students usually have two 50- to 60-minute lessons per week. Although learning environments in secondary school English classes are mostly secure and supportive, motivation to engage in activities in English lessons is generally low. Lessons are invariably constructed around commercially-produced learning materials, teachers tend to adopt 'one-size-fits-all' approaches, and little use is made of digital technologies. Few opportunities for oral interaction are on offer and the consistent use of English throughout a lesson is rare. Students describe English classes as mundane and lacking challenges. They also report being more comfortable using English outside school than inside (Swedish Schools Inspectorate 2011; see also Henry 2014).

\section{Participants}

The participants were 116 first-year upper secondary students $(\mathrm{m}=61, \mathrm{f}=55)$ taking a compulsory CEFR B1.2-level course in English at an upper secondary school in a medium- 
sized provincial town in the West of Sweden. In terms of socio-economic and ethnic background, the student population at the school does not differ to any great degree from the general population of 16 to 19 year-olds in Sweden. The participating students are the total populations of four programs (social sciences, natural sciences, art and design, and technology) providing entry qualifications for higher education. A sample of this is size is appropriate for the method of analysis used in the study as there is a long-standing consensus that in SEM the asymptotic properties of the maximum likelihood estimator can be relied upon with samples around $\mathrm{N}=100$.

\section{Instrumentation}

A questionnaire comprised of a criterion measure (intended effort in school) and separate measures for hypotheses 1 - 3 was used. Questionnaire items are provided in the online Supplementary Data.

\section{Criterion measure}

To measure intended effort expended on learning English in school, four items employing 5point Likert response options and adapted from Taguchi, Magid and Papi (2009) (3 items) and Csizér and Kormos (2009) (1 item) were used.

\section{H1: Ideal and Current L2 Selves}

To measure students’ Ideal and Current L2 Selves, two scales employing 5-point Likert response options were used. Five items adapted from those used by Ryan (2009) measured the Ideal L2 Self. Six similarly formulated items measured the Current L2 Self.

\section{H2: Attributions}


To measure attributions relating proficiency in English to instructed learning, three items focusing on work in school, homework and teaching were used. These were adapted from measures used by Tremblay and Gardner (1995) to measure similar attributions (in turn adaptations of Multidimensional-Multiattributional Causality Scale items (Lefcourt, von Baeyer, Ware and Cox 1979)). To measure the attribution relating proficiency in English to natural ability a similarly formulated single item was used. To measure attributions relating proficiency in English to naturalistic out-of-school encounters one item ('Locus of Learning') allowing 5 response options was used. This item had previously been included in a questionnaire administered in a survey of Swedish students' $(n=2868)$ beliefs and attitudes to learning English (reported in Henry 2014). Here substantially more than half believed they had learned more, or as much English outside school, 16\% believing they had learnt most or nearly all of their English outside school.

\section{H3: Self-authenticity}

To measure perceptions of supressed experiences of self-authenticity using English in school, a scale consisting of four specially created items was used.

\section{Piloting and procedures}

A pilot questionnaire was administered to a class of 35 first-year upper secondary students enrolled on similar programs at a different school. During the administration students were invited to draw attention to formulations they perceived difficult to understand. Notes were made of their comments. Immediately afterwards six students participated in a 35-minutelong focus-group discussion, going through the questionnaire again, item-by-item, thinking aloud as they responded. Minor reformulations of certain items were made as a result. 
The questionnaire proper was administered to study participants personally by the first author in December 2013. The administrations took place in the students' ordinary classrooms during morning lessons. On each occasion the first author was assisted by at least one research assistant. Class teachers were present throughout the administrations.

\section{Results}

\section{Missing data}

The total amount of internal missing data were 14 scores distributed across the totality of items. Although the amount of missing variables is very small, in order to include all the collected information the missing data modeling procedure implemented in Mplus was used (Muthén, Kaplan and Hollis 1987). This procedure yields unbiased estimates under relatively moderate assumptions, all fully satisfied in the current study (Allison 2003; Schafer and Graham 2002).

\section{Hypotheses 1a and $1 b$}

To test Hypotheses 1a and 1b comparisons were made with results from 5 reference studies (Csizér and Lukács 2010; Dörnyei and Chan 2013; Kim 2014; Ryan 2009; Papi 2010), each carried out with similarly-aged students and each reporting (i) mean scores for a measure of the Ideal L2 Self, and (ii) correlations with a criterion variable of intended effort in school (see Table 1). These studies were conducted in settings (Hungary, Hong Kong, Korea, Japan and Iran respectively) where both available literature and anecdotal evidence indicate that, in comparison to the current study, (i) English is not as extensively encountered in leisure-time activities and out-of-school domains, and (ii) proficiency is not as high. While the mean score of 4.27 ( $\mathrm{sd}=0.713$ ) obtained for the Ideal L2 Self measure in the current study is similar to those reported in those reference studies using 5-point Likert scales (where it ranges between 
3.72 and 4.49), the correlation with the criterion measure of intended effort in school $(\mathrm{r}=.34)$ is substantially lower (the range in the reference studies being between .62 and .75). This means that the variance in intended effort accounted for by the Ideal L2 Self in the current Swedish context (11.5\%) is substantially lower than in all of the reference studies (where the range is between $38.5 \%$ and $56 \%$ ).

[TABLE 1 NEAR HERE]

\section{Hypothesis 1c}

To test Hypothesis 1c, structural equation modelling (SEM) was carried out using Mplus (version 5) (Muthén and Muthén 2009) under the STREAMS (Gustafson and Stahl 2005) environment. The aim was to ascertain (i) the extent of the discrepancy and (ii) the degree of variance in the criterion variable accounted for.

As measures of model fit, the $\chi^{2}$ goodness-of-fit test and the root mean square error of approximation (RMSEA) were used. For those cases where the $\chi^{2}$ goodness-of-fit test did not produce significant results, additional goodness-of-fit measures were deemed unnecessary. Where the $\chi^{2}$ goodness-of-fit test yielded a significant result, the RMSEA was used. Here an acceptable model fit is indicated by values less than 0.08 , while values less than 0.05 imply a good model fit.

First, measurement models for effort (Effort), the Current L2 Self (Curr) and the Ideal L2 Self (Ideal) were tested to confirm the factor loadings and to ascertain the acceptability of the model fit. These models, referred to respectively as Model A, Model B and Model C, are shown in Figures 1, 2 and 3.

[FIGURE 1 NEAR HERE] 


\section{[FIGURE 2 NEAR HERE]}

\section{[FIGURE 3 NEAR HERE]}

Goodness-of-fit was good for all the three models (see Table 2). The standardized factor loadings for Model A ranged from 0.42 to 0.79, for Model B from 0.74 to 0.92, and for Model C from 0.58 to 0.84 , all of which were significant.

\section{[TABLE 2 NEAR HERE]}

The difference between the Current L2 Self $(m=4.124, \mathrm{sd}=0.877)$ and the Ideal L2 Self $(m=4.272$, $s d=0.713)$ was 0.148 . The Cohen's $d$ was 0.19 (which is small). To investigate the variance on the criterion variable (intended effort in school) explained by this difference, a nested factor model including the three measures was specified and tested. With the nested factor approach, a general latent variable is identified for a domain of observations, along with narrow latent variables which account for observed differences on subsets of variables. Such a modeling approach is suitable in this case because we are interested in determining the difference between the Current L2 Self and the Ideal L2 Self. A latent variable model was constructed in such a manner that there is one general variable (Gen) which represents the variance common to the Current L2 Self and the Ideal L2 Self, and one narrow latent variable (Diff) which represents the difference between the two types of L2 self. The narrow latent Diffvariable was further related to the latent Effort-variable. Goodness-of-fit for the model (Model D) was acceptable (see Table 2) ${ }^{\mathrm{ii}}$. The standardized factor loadings, all significant, are shown in Figure 4. The factor loading for Diff on Effort was 0.39 (t-value=3.696). This implies that the variance in effort accounted for by the difference between the Current L2 Self and the Ideal L2 Self was $15.2 \%$. 
[FIGURE 4 NEAR HERE]

\section{Hypotheses $2 a$ and $2 b$}

To test Hypotheses 2a and 2b, modelling procedures identical to those described above were carried out. Five models were created, each attribution variable separately related to the latent Effort-variable (Model A, see Figure 1):

- the Work in School attribution variable (Model E:1)

- $\quad$ the Homework attribution variable (Model E:2)

- the Teaching attribution variable (Model E:3)

- the Natural Ability attribution variable (Model E:4)

- the Locus of Learning attribution variable (Model E:5)

Estimates for each of these models are provided in Table 3.

\section{[TABLE 3 NEAR HERE]}

Positive correlations between the attribution and criterion variables were found for Models E:1, E:2 and E:3. A negative correlation between attribution and criterion variables was found for Model E:5. There was no significant correlation for Model E:4.

\section{Hypothesis 3}

To test Hypothesis 3 modelling procedures identical to those previously described were carried out. Two models were created. First a measurement model for self-authenticity (Model F; Figure 5), and then a model including both effort and self-authenticity, with a relation between the two latent variables (Model G; Figure 6). 


\section{[FIGURE 5 NEAR HERE]}

\section{[FIGURE 6 NEAR HERE]}

Goodness-of-fit and p-values for the two models are provided in Table 4.

\section{[TABLE 4 NEAR HERE]}

The results indicate a negative although non-significant relationship between the predictor variable (perceptions that use of English in classroom settings lacks the self-authenticity of experiences of language use outside of the classroom) and the criterion variable (intended effort in school).

\section{Discussion}

\section{Hypothesis 1}

In comparison with the findings reported in the reference studies, the scores of the current participants on the Ideal L2 Self scale were, as hypothesised, similar or indeed greater. At the same time the correlation between the Ideal L2 Self and the criterion measure (intended effort in school) was markedly lower. The most plausible explanation for this lies in the nature of the discrepancy between the Current L2 Self and the Ideal L2 Self which, as we have shown, plays only a moderate role in accounting for the variance in intended effort in school. Although it is impossible to compare the size of this discrepancy with other studies (current L2 selves not normally being measured), the finding indicates that the magnitude is not sufficient to generate motivation of a degree similar to that found in secondary school settings in other parts of the world (or for that matter characteristic of the Ideal L2 Self construct 
generally, where it normally explains more than $40 \%$ of the variance on criterion measures (Dörnyei and Ryan, 2015)).

As made clear in the description of the study's setting, English is an integral part of the social environment in which young people in Sweden grow up. Not only are competence levels high, but many young people regularly engage in creative and identity-relevant activities that are English-mediated, such as, for example, digital gaming and posting texts on Internet forums. For these reasons the L2 identities of the students surveyed here are likely to differ from those of similarly-aged counterparts in the settings in which the reference studies were conducted. Whether the strength of the Current L2 Self is understood in the sense that these students are close to fully achieving a bicultural identity (i.e. an identity encompassing a robust English-speaking global identity alongside a local identity), or that they have hybrid identities (where being a globally-involved, English-speaking person is central in experiences of selfhood), the conception of the self as an English-user/speaker is not so much a distal, idealized state to be aspired to or aimed at, as an immanent dimension of the learner's current identity.

\section{Hypothesis 2}

The findings that attributions relating proficiency in English to aspects of instructed learning (schoolwork, teaching and homework) were positively related to the criterion measure (intended effort in school), thus supporting the first hypothesis (2a), are hardly surprising. Students who believe they develop skills in English largely due to instruction, work undertaken in school and time spent doing homework are more motivated to study in school.

For the second hypothesis (2b) - that attributions relating proficiency in English to natural ability and naturalistic out-of-school encounters would be negatively related to the same criterion measure - the results were mixed. While a belief that most of what is known in 
English had been learned outside of school was negatively correlated with the criterion measure (intended effort in school), for the attribution relating proficiency in English to natural ability, support was not found for the hypothesised negative relation. While the first of these findings aligns with Ryan and Mercer’s (2011) 'fixed language learning mindset' conceptualisation, in relation to the second - beliefs held about the primacy of natural ability (the centrepiece of a 'fixed mindset') - the findings did not offer support. These results seem again to be related to the presence and status of English.

In the setting investigated here, the presence of English is pervasive. It is not a 'foreign' language in the sense it is in settings were encounters and use in everyday environments are less extensive. Although it needs to be emphasised that, in relation to English, children in Sweden are not growing up in a societally bilingual/multilingual environment (i.e. where outside of home and school social interaction takes place in a different language), they do nevertheless find themselves in environments where English 'co-exists' (Edwards 2004) alongside Swedish. Thus it is more than simply a ‘background presence’ (Ryan and Mercer 2011: 166).

Consequently, while there is a powerful logic to the idea that holding a belief that English is mostly learnt outside school can impact negatively on the sense of urgency with which classroom learning is undertaken, it does not follow that a sense of possessing a natural talent for learning English will have the same effect. For some students, holding a belief about the possession of natural talent could certainly encourage a 'slackening off' in classroom learning, reliance placed instead on their innate talents to forge a pathway to success (especially given the wealth of learning opportunities in informal environments). Others, however, may value the more theoretically-oriented nature of classroom learning. For these students instructed environments can provide them with opportunities that enable them to more fully experience and express the range of their perceived talent. Indeed, in classroom 
settings, such learners could be spurred on by experiences of self-efficacy and welcome opportunities to demonstrate ability. Although further research would be needed to investigate the relationship between the two types of belief incorporated in Mercer and Ryan's 'language learning mindset' theory, the current findings suggest that in contexts where English is more than just a 'background presence' in the learner's mind, and is constituent in many common social practices, belief constellations may differ.

\section{Hypothesis 3}

Although, as predicted, the results indicate a negative relationship between students' perceptions of experiencing supressed self-authenticity using English in school and the criterion measure of intended effort, the magnitude was not such to achieve statistical significance. While it is not possible to draw any conclusions about students' motivated behaviour on the basis of this result, interesting methodological issues arise. These are addressed in the general discussion.

\section{General discussion}

There are a number of important issues, conceptual, methodological and pedagogical, arising from this study. Considering first the question of conceptualisations of identity in L2 motivation and the discrepancies between current and ideal L2 selves, one of the most important conclusions is methodological. It needs to be recognised that designs incorporating measures of the Ideal L2 Self capture only one element of a dichotomic process. Since much of the current research adopting a possible selves approach continues to be conducted in parts of the world (notably Japan, but also China, Hungary and Iran) where English is not generally encountered in everyday environments, where levels of proficiency tend not to be as high as 
for example in Northern Europe, and where people are likely to have robust local identities, measurement of the Ideal L2 Self in isolation is not perhaps a problem. It is fully reasonable, as the reference studies cited here clearly indicate, to assume that a substantial discrepancy between current and ideal L2 selves does exist. However, in that globalisation is leading to a growing number of contexts where the everyday presence and use of English in social practices is increasing, and English is becoming ever-more constituent in younger people's lives, this is an assumption that can become problematic. Consequently in the design of research carried out in settings where English has a strong social and/or societal presence, it would be advisable to include measures of both current and ideal L2 selves. This, as MacIntyre and his colleagues rightly identified at the outset of possible selves-based L2 motivation research, is important. As they make clear, the 'advantage of using a possible selves approach lies in the comparison of the present and future states [and in] highlighting the discrepancy between them to understand the sources of language learning motivation' (Macintyre, Mackinnon and Clément 2009: 209).

In addition to this important methodological consideration, the question of the magnitude of the discrepancy has pedagogical implications. In contexts where English is becoming an increasingly important constituent in young people’s social and discourse practices, the gap to be reduced between current and ideal selves may be rather small. Thus the Ideal L2 Self may not generate the degree of motivation that it normally does, the construct usually emerging as the single most important source of motivation (Dörnyei and Ryan 2015). How, then, should teachers take account of this in their practice? MacIntyre, Mackinnon and Clément (2009) suggest, for example, that in situations where 'the self describes a respondent both now and in the future, motivation for language learning and maintenance of the L2 self likely would come primarily from the feared self' (208). The longer-term efficacy of strategies directed to triggering students’ feared L2 selves may however be questionable; nor might such an 
approach always be pedagogically appealing. Rather, in contexts such as that in focus here, a more productive strategy might be to focus on aspects of ideal self-images that may, or could potentially differ from current selves. Using the types of vision-generating techniques advocated by Dörnyei and Kubanyiova (2014), teachers could encourage students to focus on and/or develop aspects of their ideal L2 self not currently included in their current L2 selves. In particular, for students who perceive themselves as comfortable, skilled speakers/users of English in social domains (see e.g. Swedish Schools Inspectorate 2011; Henry 2014), it might be of value to offer them opportunities to embellish and expand their ideal L2 selves by generating self-in-future images in the types of professional, vocational, and higher education domains that English language programs are designed to prepare them for.

Turning to the impact that students' beliefs about natural ability and naturalistic acquisition have on motivated behaviour, as Ryan and Mercer (2012) make clear, 'language learning mindsets' can differ across social, cultural and educational contexts. It is also unlikely, as commented on by the reviewers of this paper, that a learner can be characterised solely in terms of having one type of mindset, or of possessing an implicit theory of learning that is forever 'fixed'. Not only do learners usually hold a range of beliefs, meaning they can be placed on a continuum depending on how strongly such beliefs are held, but as a consequence of contextual changes their position on such a continuum will generally shift. Thus it follows that the nature of the discussions that teachers need to have with students about potentially learning-impeding beliefs will need to differ depending both on the individual student, and the particularities of the context in which teaching takes place (for an excellent discussion of these issues see Gregersen and MacIntyre, 2014). For teachers of English whose students participate in English-mediated free-time activities (or who return to the class after a study abroad period), time spent talking with them about the beliefs they may hold about the primacy of language learning in naturalistic environments could have an important impact on 
approaches to classroom learning. However, in relation to beliefs about aptitude, while efforts directed to dispelling these types of inhibiting belief might have positive effects in settings such as Austria or Japan (the countries in which Mercer and Ryan carried out their research), in a Swedish setting time devoted to a similar cause may not be equally effective. Consequently it becomes important for teachers to gain insights into the specific nature of students' particular language learning experiences and beliefs, and where they might be placed on the 'mindset continuum'.

Finally, turning to the question of differing experiences of self-authenticity and the effects that self-appraisals can have on motivation, it is entirely possible that perceptions of suppressed self-authenticity may not impact (either directly or indirectly) on effort expended in the classroom. However it is also possible that the non-significant result has a methodological explanation. First, it needs to be pointed out that, compared to beliefs and L2 self-guides, individuals’ appraisals of self-authenticity are to a much greater degree situationally determined. As Vannini and Burgess (2009) make clear, self-authenticity appraisals take place within the context of ongoing activities. Thus, even though L2 selfguides are dynamic constructs, subtly changing whenever they are activated (Henry 2015; Markus and Kunda 1986), experiences of self-authenticity can differ more dramatically from one moment to the next. This can make self-authenticity appraisals difficult to capture using context-independent measurement techniques such as questionnaires, a fact recognised by symbolic interactionist researchers working with state self-authenticity who, like Vannini and Burgess (2009), generally employ research designs involving semi-structured interviews.

The second methodological issue that may explain the result is that, in any student group, there is likely to be a range of varying experiences of encounters with English in naturalistic contexts. In suggesting that experiences of frustrated authenticity could negatively affect classroom motivation, Henry’s (2013) proposals are made in relation to digital gaming which, 
as an ever-growing number studies in the CALL field make clear, can provide rich and rewarding English-mediated experiences (see e.g. Peterson, 2010). It is certainly true that large numbers of young people in Sweden do play English-mediated digital games, and engage in other creative activities that are mediated in English (e.g. writing fan fiction or contributing to internet forums). However it needs also to be recognised that many free-time activities involving English (net-surfing, watching TV, films and video clips, and listening to music) are largely receptive. Furthermore, there is substantial variation in free-time exposure to/use of English, some young people having very few contacts (Sundqvist, 2009). Students who have few free-time contacts with English, or for whom largely receptive experiences lack the intensity of more creative and interactive activities, are unlikely to experience a similar sense of 'frustratedness' in class. Consequently, in order to ascertain whether experiences of frustrated authenticity impacting on classroom behaviour can be found in a general population of students or whether the phenomenon might only be characteristic for certain groups, a sample of sufficient seize to enable the hypothesis to be tested for different sub-groups (as a factor of the nature of English-mediated activities engaged in) would be needed.

\section{Conclusion}

The success that Dörnyei’s (2005) reconceptualization of L2 motivation as a process of selfdiscrepancy has had in shedding light on second language learners' motivation is genuinely remarkable. Not only has the paradigm been embraced by researchers from all corners of the globe, but in the ten years since the launch of the L2 Motivational Self System model, over a hundred empirically-based journal articles and anthology chapters have confirmed the applicability of possible selves theory to language learning motivation, and the validity of its central component, the Ideal L2 Self, in accounting for motivated behaviour (Dörnyei \& Ryan, 2015). Not only is the Ideal L2 Self now a widely recognised concept in SLA, but 
through practitioner-oriented volumes (Dörnyei and Kubanyiova, 2014; Dörnyei, Henry and Muir, 2016; Hadfield \& Dörnyei 2013; Gregersen and MacIntyre, 2014), it has also found its way into language classrooms.

However, when a paradigm as powerful as the self-system approach achieves a dominant status in its field there is a risk that central concepts are adopted uncritically and anomalies ignored (Khun 1962). Framed within Ushioda’s (2013) observation of the increasing difficulty of characterising interactions between motivation and context in general terms, the current study suggests that, in settings where English has become a part of everyday cultural practices and experiences, the strength of individuals' current L2 selves can mean that the idealized version - the English-speaking future self - lacks the power to align motivated behaviour in a manner consistently demonstrated in other contexts.

Given the increasingly diverse and localised settings which, in the current era of gloablisation, language learning takes place, it becomes necessary to consider the relative prominence and strengths of learners' ideal and current selves. This is important not only for conceptual reasons, but also in terms of the implications for pedagogy in that teachers' visionenhancement techniques need to be aligned with the nature of the relationship between learners' 'now' and 'future' L2 selves. In the current context, we have argued, teachers may need to more narrowly direct the focus of L2 self-enhancing techniques to those dimensions of students' ideal selves that may be underdeveloped. Similarly, given that the findings indicate that in the type of context investigated here, beliefs about the optimal nature of naturalistic learning can have negative effects on classroom motivation, there is a need to problematize such beliefs. The current study also indicates that work could usefully be carried out identifying other factors that, in contexts newly emerging as a consequence of continuing globalization, can influence students' motivation to learn English. In this regard learners’ appraisals of self-authenticity appear as an avenue of enquiry that is particularly worthwhile. 
Finally, given that the current study drew exclusively on questionnaire-generated data, interview-based studies where each of the three phenomena investigated could be examined in greater depth would be of significant value.

\section{Acknowledgments}

In addition to the students and teachers at schools where the questionnaire was piloted and administered, we would also like to thank the three anonymous reviewers and Anna Mauranen for the excellent comments we received during the review process. We would also like to thank Kata Csizér for generously making her data available to us. To all of you we are greatly indebted.

\section{References}

Airey, J. 2009. Science, Language and Literacy: Case Studies of Learning in Swedish University Physics. Uppsala Dissertations from the Faculty of Science and Technology.

Allen, G. 2011. Intertextuality. London: Routledge.

Allison, P.D. 2003. 'Missing data techniques for structural equation modeling.' Journal of Abnormal Psychology, 112/4: 545-557.

Arnett, J. 2002. ‘The psychology of globalization.’ American Psychologist, 57: 774-783.

Barcelos, A.M.F. 2003. 'Researching beliefs about SLA: A critical review.' In P. Kalaja and A.M.F Barcelos (eds.) Beliefs About SLA: New Research Approaches. Kluwer.

Brown, T. A. 2006. Confirmatory factor analysis for applied research. New York: Guilford Press.

Cabau, B. 2009. 'The irresistible rise and hegemony of a linguistic fortress: English teaching in Sweden.’ International Multilingual Research Journal 3: 134-152. 
Canagarajah, S. 2007. 'Lingua franca English, multilingual communities, and language acquisition.' The Modern Language Journal 91: 923-939.

Csizér, K. and J. Kormos. 2009. 'Learning experiences, selves and motivated learning behavior: A comparative analysis of structural models for Hungarian secondary and university learners of English. In Z. Dörnyei and E. Ushioda (eds.).

Csizér, K. and G. Lukacs. 2010. ‘The comparative analysis of motivation, attitudes and selves: The case of English and German in Hungary.' System 38: 1-13.

Dörnyei, Z. 2005. The Psychology of the Language Learner: Individual Differences in Second Language Acquisition. Lawrence Erlbaum.

Dörnyei, Z. and L. Chan. 2013. 'Motivation and vision: An analysis of future L2 self images, sensory styles, and imagery capacity across two target languages.’ Language Learning Language Learning 63: 437-462.

Dörnyei, Z. and M. Kubanyiova. 2014. Motivating Learners, Motivating Teachers. Cambridge University Press.

Dörnyei, Z., A. Henry and C. Muir. 2016. Motivational Currents in Language Learning: Frameworks for Focused Interventions. Routledge.

Dörnyei, Z. and S. Ryan. 2015. The Psychology of the Language Learner: Individual Differences in Second Language Acquisition. Routledge.

Dweck, C. S. 1999. Self-theories: Their Role in Motivation, Personality and Development. Psychology Press.

Edwards, V. 2004. Multilingualism in the English-speaking World. Blackwell.

Erling, E.J. 2007. 'Local identities, global connections: affinities to English among students at the Freie Universität Berlin.’ World Englishes, 26/2 111-130. 
Gardner, R.C. and W.E. Lambert. 1972. Attitudes and Motivation in Second Language Learning. Newbury House.

Gregersen T. and P. D. MacIntyre. 2014. Capitalizing on Language Learners’ Individuality: From Premise to Practice. Multilingual Matters.

Gustafsson, J.E. and P.A. Stahl. 2005. STREAMS 3.0 User's Guide. Multivaraiteware.

Hadfield, J. and Z. Dörnyei. 2013. Motivating learning. Harlow: Longman.

Hayes, E.R. and J.P. Gee. 2010. ‘Popular culture as a public pedagogy: Design, resources and affinity spaces.' In A. Sandlin, B. Schultz, and J. Burdick (eds), Handbook of Public Pedagogy. Routledge.

Henry, A. 2013. 'Digital gaming and ELT: Bridging the authenticity gap’. In E. Ushioda (Ed.). International perspectives on English language teaching: Motivation. Houndmills: Palgrave McMillan.

Henry, A. 2014. 'Swedish students' beliefs about learning English in and outside of school'. In D. Lasagabaster, A. Doiz and J.M. Sierra (Eds.). Motivation and Foreign Language Learning: From Theory to Practice. Amsterdam: John Benjamins.

Henry, A. 2015. 'The dynamics of possible selves'. In Z. Dörnyei, P.D. Macintyre and A. Henry (eds), Motivational Dynamics in Language Learning. Multilingual Matters.

Henry, A. and A. Goddard. 2015. 'Bicultural or hybrid? The second language identities of students on an English-mediated university program in Sweden'. Journal of Language and Identity in Education. 255-274.

Hermans H.J.M. and G. DiMaggio. 2007. 'Self, identity, and globalisation in times of uncertainty: A dialogical analysis.' Review of General Psychology 11: 31-61.

Higgins, E.T. 1987. Self-discrepancy: A theory relating self and affect. Psychological Review 94: 319-340. 
Hong, Y.Y., C.Y.Chiu, C.S. Dweck, D. Lin and W. Wan. 1999. 'Implicit theories, attributions, and coping: A meaning system approach.' Journal of Personality and Social Psychology, 77/3: 588-599.

Hsieh, P. H. and D.L. Schallert. 2008. 'Implications from self-efficacy and attribution theories for an understanding of undergraduates' motivation in a foreign language course.' Contemporary Educational Psychology 33: 513-532.

Huta, V. and A. S. Waterman. 2013. 'Eudaimonia and its distinction from hedonia: Developing a classification and terminology for understanding conceptual and operational definitions’. Journal of Happiness Studies, 15, 1425-1456.

Kernis, M. H. and B. M. Goldman. 2006. ‘A multicomponent conceptualization of authenticity: Theory and research'. Advances in Experimental Social Psychology, 38, 283-357.

Kim, T.Y. and Y.K. Kim. 2014. 'A structural model for perceptual learning styles, the ideal L2 self, motivated behavior, and English proficiency’. System 46: 14-27.

Kline, R. B. 2010. Principles and Practice of Structural Equation Modeling (Third Edition) (Methodology in the Social Sciences). New York: Guilford Press.

Kramsch, C. 2012. 'Authenticity and legitimacy in multilingual SLA'. Critical Multilingualism Studies, 1:1 107-128.

Kuhn T.S. 1962. The structure of scientific revolutions. Chicago, IL: University of Chicago Press.

Kuppens, A.H. 2010. 'Incidental foreign language acquisition from media exposure.' Learning, Media and Technology, 35:1 65-85.

Lamb, M. 2004. 'Integrative motivation in a globalizing world.' System 32/3: 3-19.

Lambert, W. 1972. 'A social psychology of bilingualism', in A. S. Dil (ed.), Language, Psychology and Culture. Essays by Wallace E. Lambert. Stanford University Press. 
Lefcourt, H. M., C.L. von Baeyer, E.F. Ware and D.J. Cox. 1979. 'The multidimensionalmultiattributional causality scale: The development of a goal specific locus of control scale.' Canadian Journal of Behavioural Science, 11: 286-304.

MacIntyre, P.D., S.P. Mackinnon and R. Clément. 2009. 'Toward the development of a scale to assess possible selves as a source of language learning motivation. In Z. Dörnyei and $\mathbf{E}$. Ushioda (eds.).

Markus, H. and Z. Kunda. 1986. 'Stability and malleability of the self-concept.' Journal of Personality and Social Psychology 51/4: 858-866.

Mercer, S. and S. Ryan. 2010. 'A mindset for EFL: Learners' beliefs about the role of natural talent.’ ELT Journal 64: 436-444.

Mercer, S., S. Ryan and M. Williams. 2012. Psychology for Language Learning. Multilingual Matters.

Mills, N., F. Pajares and C. Herron. 2007. 'Self-efficacy of college intermediate French students: Relation to achievement and motivation.’ Language Learning, 57: 417-422.

Murray, G., X. Gao and T. Lamb. 2011. Identity, Motivation and Autonomy in Language Learning. Multilingual Matters.

Muthén, B., D. Kaplan and M. Hollis. 1987. 'On structural equation modelling with data that are not missing completely at random.' Psychometrica, 52/3: 431-462.

Muthén, L.K. and B. Muthén. 2009. Mplus User's Guide (5 ${ }^{\text {th }}$ edition). Muthén and Muthén.

Olsson, E. 2011. 'Everything I read on the Internet is in English': On the Impact of Extramural English on Swedish 16-year-old pupils’ Writing Proficiency. University of Gothenburg.

Papi, M. 2010. 'The L2 motivational self system, L2 anxiety, and motivated behavior: A structural equation modeling approach.’ System 38: 467-479. 
Piirainen-Marsh, A. and L. Tainio. 2009. Other-repetition as a resource for participation in the activity of playing a video game. The Modern Language Journal, 93/2: 153-169.

Peterson, M. 2010. Massively multiplayer online role-playing games as arenas for second language learning. Computer Assisted Language Learning, 23/5: 429-439.

Ryan, S. 2009. 'Self and identity in L2 motivation in Japan: The ideal L2 self and Japanese learners of English.’ In Z. Dörnyei and E. Ushioda (eds.).

Ryan, S. and S. Mercer. 2011. 'Natural talent, natural acquisition and abroad: Learner attributions of agency in language learning.’ In G. Murray, X. Gao, and T. Lamb (eds.).

Ryan, S. and S. Mercer. 2012. 'Implicit theories: Language learning mindsets.’ In S. Mercer, S. Ryan and M. Williams (eds.).

Schafer, J.L. and J.W. Graham. 2002. 'Missing data: Our view of the state of the art.' Psychological Methods, 7/2: 147-177.

Stracke, E., J. Jones and N. Bramley. 2014. 'Investigating adult migrant ESL learners' language learning motivational profile in Australia: Towards a bicultural identity. In $\mathbf{K}$. Csizér and M. Magid (eds.). The impact of self-concept on language learning. Multilingual Matters.

Sundqvist, P. 2009. Extramural English Matters: Out-of-school English and its Impact on Swedish Ninth Graders’ Oral Proficiency and Vocabulary. Karlstad University Studies.

Sundqvist, P. and L.K. Sylvén. 2014. 'Language-related computer use: Focus on young L2 English learners in Sweden.' ReCALL 26/1: 3-20.

Sylvén, L.K. 2013. 'CLIL in Sweden - why does it not work? A metaperspective on CLIL across contexts in Europe'. International Journal of Bilingual Education and Bilingualism, 16/3: 301-320. 
Sung, C.C.M. 2014. 'Global, local or glocal? Identities of L2 learners in English as a Lingua Franca communication’ Language, Culture and Curriculum 27/1: 43-57.

Swedish Media Council. 2013. Ungar och Mediar 2012/2013: Fakta om Barns och Ungas Användning och Upplevelser av Medier (Young People and the Media 2012/2013: Facts on Children and Young People’s Media Use and Experiences). Statens Media Råd.

Swedish Schools Inspectorate. 2011. Kvalitetsgranskning: Engelska i Grundskolans Årskurser 6-9. (Quality Evaluation: English in Secondary School Grades 6 -9). Swedish Government.

Taguchi, T., M. Magid and M. Papi. 2009. The L2 Motivational Self System among Japanese, Chinese and Iranian learners of English: A comparative study. In Z. Dörnyei and E. Ushioda (eds.).

Taylor, F. 2013. 'Listening to Romanian teenagers: Lessons in motivation and ELT methodology’ in E. Ushioda (ed.).

Tremblay, P. and R.C. Gardner. 1995. 'Expanding the Motivation Construct in Language Learning.' The Modern Language Journal 79/4. 505-518.

Ushioda, E. 2011. 'Language learning motivation, self and identity: current theoretical perspectives.' Computer Assisted Language Learning 3: 199-210.

Ushioda, E. 2012. 'Motivation: L2 Learning as a Special Case?’ In S. Mercer, S. Ryan and M. Willimams (eds).

Ushioda, E. 2013. International Perspectives on Motivation: Language Learning and Professional Challenges. Palgrave Macmillan.

Vannini, P. and S. Burgess. 2009. 'Authenticity as motivation and aesthetic experience.' In P. Vannini and J. Patrick Williams (eds.) Authenticity in Culture, Self and Society. Ashgate Publishing. 
World Economic Forum. 2012. Global Information Technology Report. WEF.

Figures 1-6 and Tables 1-4

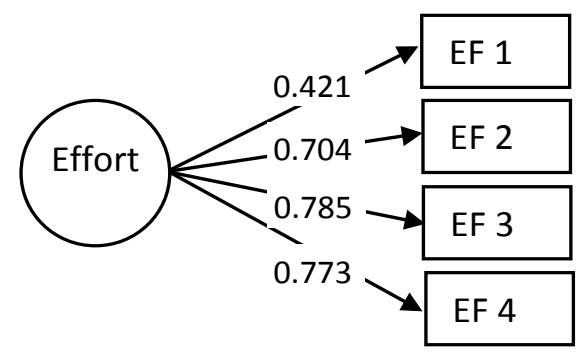

Figure 1. Measurement model for Effort (Model A).

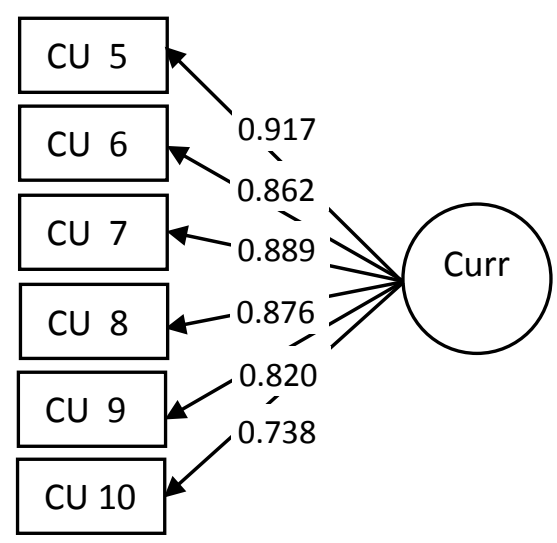

Figure 2. Measurement model for the Current L2 Self (Model B).

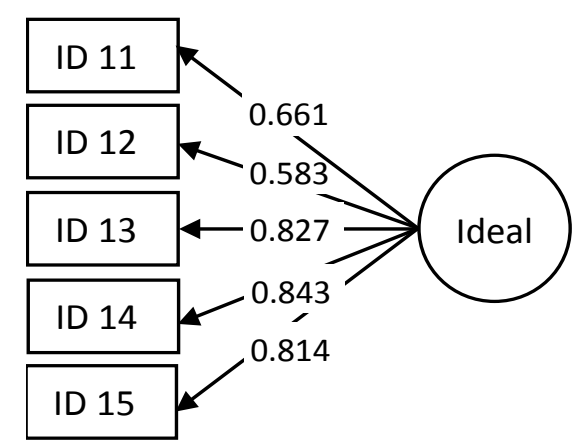

Figure 3. Measurement model for the Ideal L2 Self (Model C). 


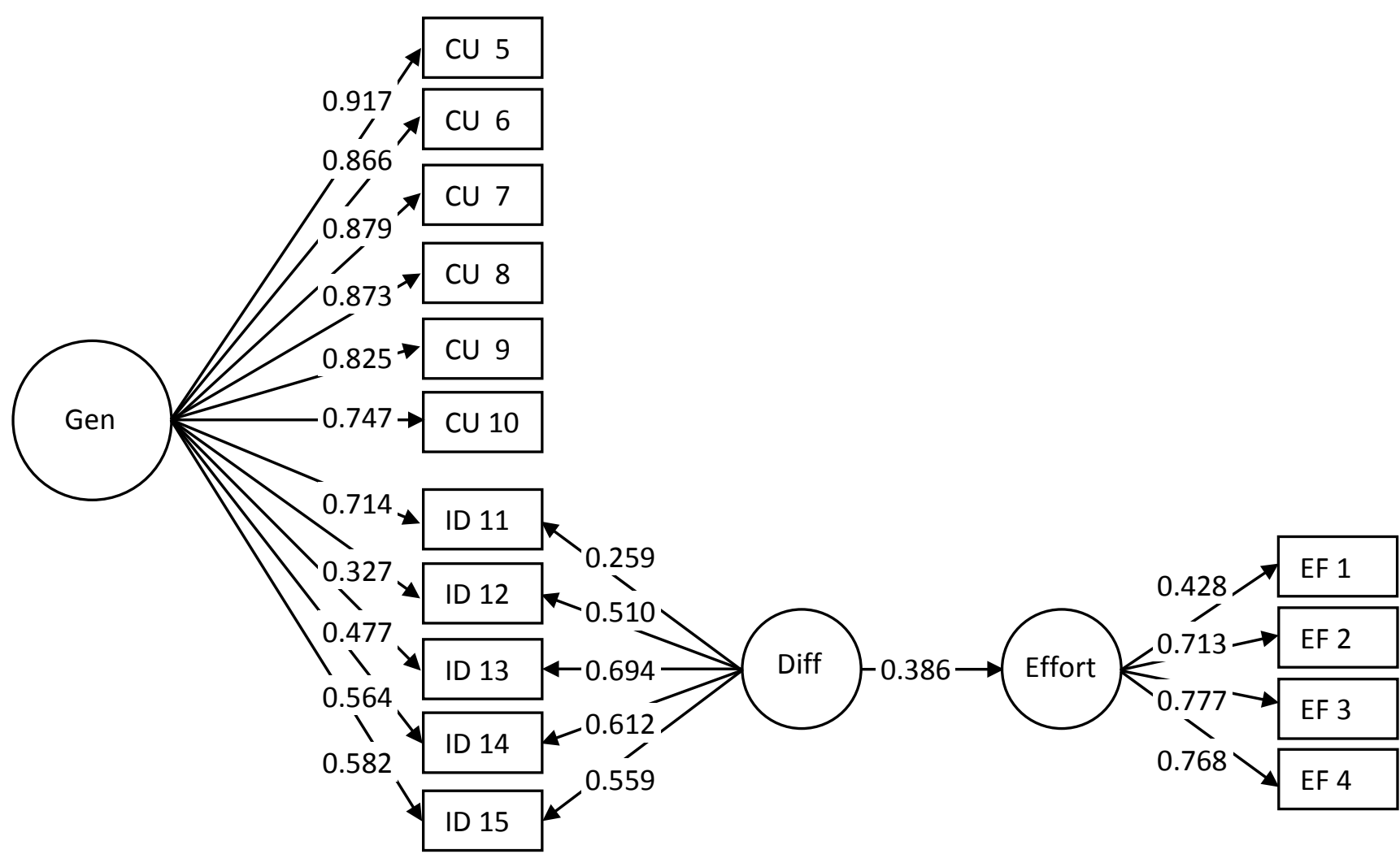

Figure 4. Difference between the Current L2 Self and the Ideal L2 Self on Effort (Model D).

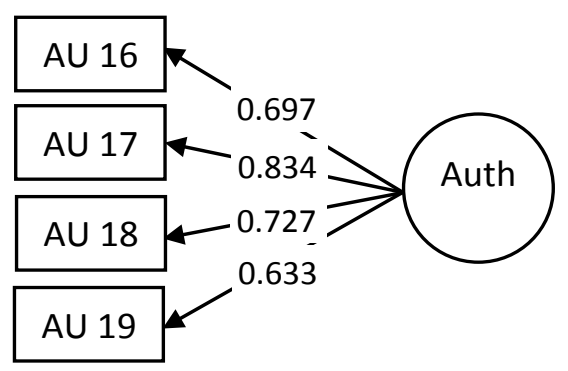

Figure 5. Measurement model for Self-authenticity (Model F) 


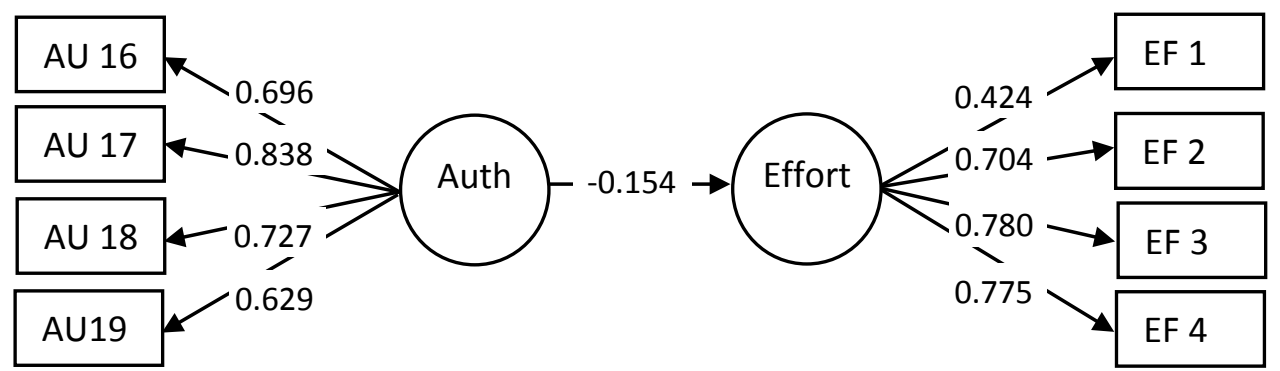

Figure 6. Self-authenticity on Effort (Model G).

Table 1. Comparisons with reference studies for mean scores for the Ideal L2 Self measured on 5-point Likert scales and correlations with criterion measures (Effort).

\begin{tabular}{llllll}
\hline Study & $r$ & Setting & Students & $n$ & mean \\
\hline Current study & .34 & Sweden & $16 / 17$ yrs & 116 & 4.27 \\
Csizér \& Lukacs (2010)* & $.69^{* *}$ & Hungary & $16 / 17$ yrs & 100 & 4.49 \\
Dörnyei \& Chan (2013) & .68 & Hong Kong & $13-15$ yrs & 172 & 3.62 \\
Kim (2014) & .71 & Korea & $13-15$ yrs & 378 & 3.36 \\
Kim (2014) & .69 & Korea & $16-18$ yrs & 1071 & 3.72 \\
Ryan (2009) & .75 & Japan & $15-18$ yrs & 371 & $3.43^{* * *}$ \\
Papi (2010) & .62 & Iran & $14-19 y r s$ & 1011 & $4.30^{* * *}$ \\
\hline
\end{tabular}

Note: *students studying English as L2;** calculated from author-provided dataset; *** measured on 6-point Likert scale.

Table. 2. Goodness-of-fit and p values for models A-D.

\begin{tabular}{lrll}
\hline Model & \multicolumn{1}{c}{$\chi^{2} / d f$} & $\mathrm{p}$-value & RMSEA \\
\hline $\mathrm{A}$ & $0.371 / 2$ & $0.831^{\mathrm{ns}}$ & \\
$\mathrm{B}$ & $3.169 / 9$ & $0.957^{\mathrm{ns}}$ & \\
$\mathrm{C}$ & $3.956 / 5$ & $0.556^{\mathrm{ns}}$ & \\
$\mathrm{D}$ & $136.274 / 84$ & 0.000 & 0.073 \\
\hline
\end{tabular}

Note. ${ }^{n s}=$ not significant. 
Table. 3. Standardized factor loadings, t-values, goodness-of-fit and p-values for models E1-5.

\begin{tabular}{lcccc}
\hline Model & on Effort & t-value & $\chi^{2} / d f$ & p-value \\
\hline E:1 & 0.529 & 6.742 & $8.337 / 5$ & $0.139^{\text {ns }}$ \\
E:2 & 0.464 & 5.553 & $1.348 / 5$ & $0.930^{\text {ns }}$ \\
E:3 & 0.478 & 5.768 & $8.210 / 5$ & $0.145^{\text {ns }}$ \\
E:4 & 0.064 & $0.595^{\mathrm{ns}}$ & $10.496 / 5$ & $0.062^{\text {ns }}$ \\
E:5 & -0.400 & -4.504 & $5.503 / 5$ & $0.358^{\text {ns }}$
\end{tabular}

Note. E:1= Effort incl. Work in school attribution; E:2= Effort incl.

Homework attribution; E:3= Effort incl. Teaching attribution; E:4= Effort

incl. Natural Talent attribution; E:5= Effort incl. Locus of Learning

attribution; $^{\text {ns }}=$ not significant.

Table. 4. Goodness-of-fit and p-values for models F and G.

\begin{tabular}{lcl}
\hline Model & $\chi^{2} / d f$ & $\mathrm{p}$-value \\
\hline $\mathrm{F}$ & $4.699 / 2$ & $0.0954^{\mathrm{ns}}$ \\
$\mathrm{G}$ & $12.424 / 19$ & $0.8667^{\mathrm{ns}}$ \\
\hline
\end{tabular}

Note. F= Measurement model for Self-authenticity; $G=$

Self-authenticity on Effort; ${ }^{\text {ns }}=$ not significant.

'As one of the reviewers of this paper pointed out, conceptions of identity as either 'bicultural' or 'hybrid' are reifications, of which researchers working in other areas of SLA might be critical. However in the L2 motivation field the notion of a 'bicultural identity' is the currently accepted understanding of identities that emerge in many contexts, especially where English is the target language (see Dörnyei \& Ryan, 2015). Thus, while in other fields the proposal that language learners develop hybrid identities might be criticized as reifying the concept, in the L2 motivation field the proposal involves a step forward.

ii According to some published rules of thumb (e.g., Kline, 2010), about 5 - 10 observations are needed for each estimated parameter in SEM. This would imply that the current sample size (116) is insufficient for estimating Model D (which includes 36 free parameters). However, even though a larger sample than 116 observations would certainly have been valuable, it should be noted that the number of observations is only one factor affecting the power of a SEM model. The amount of interrelations among the observed variables is another important factor (Brown, 2006), and in the current study this was substantial. The narrow confidence interval of the RMSEA estimate for Model D (0.050 - 0.095) also indicates adequate power of the model, as do small standard errors of the standardized factor loadings. 
